\title{
Capsaicin cough receptor sensitivity test in children
}

\author{
A.B. Chang*, P.D. Phelan**, R.G.D. Roberts*, C.F. Robertson*
}

Capsaicin cough receptor sensitivity test in children. A.B. Chang, P.D. Phelan, R.G.D. Roberts, C.F. Robertson. (CERS Journals Ltd 1996.

ABSTRACT: Capsaicin has been used as a tussive agent in studies in adults to determine cough receptor sensitivity. The aim of this study was to determine the tolerance, repeatability and influence of inspiratory flow on the capsaicin cough receptor sensitivity test in children.

Thirty children (mean age 11 yrs; range 6-16 yrs) were tested on two different days, to determine the lowest concentration of capsaicin required to stimulate two or more coughs (cough threshold (Cth)), 2-4 coughs (C2), and five or more coughs (C5). Capsaicin was nebulized through a dosimeter, with an arrangement that allowed the subjects to visualize and regulate their inspiratory flow.

Using a constant inspiratory flow of $20 \mathrm{~L} \cdot \mathrm{min}^{-1}$, tests were reproducible for C2, $\mathrm{C} 5$ and $\mathrm{Cth}$ (doubling dose changes of $1.13,1.03$ and 1.08, respectively). An increase in the inspiratory flow from 20 to $60 \mathrm{~L} \cdot \mathrm{min}^{-1}$ significantly increased $\mathrm{C} 2(19.5$ to $46.8 \mu \mathrm{M} ; \mathrm{p}=0.016)$ and $\mathrm{C5}(46.8$ to $128.8 \mu \mathrm{M} ; \mathrm{p}=0.008)$.

We conclude that in children, the capsaicin cough challenge test: 1) is well-tolerated; 2) is highly repeatable; and that 3 ) the inspiratory flow significantly influences cough receptor sensitivity and repeatability of the test and should, thus, be regulated.

Eur Respir J., 1996, 9, 2220-2223.
*Dept of Thoracic Medicine and **University Dept of Paediatrics, Royal Children's Hospital, Melbourne, Australia.

Correspondence: A. Chang Dept of Thoracic Medicine Royal Children's Hospital Parkville

Melbourne

Victoria 3052

Australia.

Keywords: Capsaicin

children

cough

inspiratory flow rate

Received: March 71996

Accepted after revision July 171996

$\mathrm{ABC}$ is supported by the National Health and Medical Research Council of Australia.
Capsaicin has been used as a tussive agent in studies to determine cough receptor sensitivity [1-3]. However, in contrast to histamine and methacholine challenges [4, 5], the methodology of the capsaicin cough challenge test is not yet standardized, with different laboratories using not only different delivery methods but also different inhalation methods [2, 3, 6-8]. Repeatability studies using current statistical standards [9-11] have not been performed. The method also needs modification for paediatric use, to standardize the pattern and rate of inhalation. BARROS et al. [8] showed that changes in inspiratory flow rate (IFR) may affect the results of cough challenges in healthy adults. HANSSON et al. [12], using different droplet size and IFR, demonstrated that capsaicin challenge results are affected by the site of deposition of capsaicin. Information on tachyphylaxis of capsaicin-induced cough is variable. In a study designed primarily to study tachyphylaxis, MoRICE et al. [13] reported the presence of tachyphylaxis of up to $240 \mathrm{~min}$, and yet others have reported none [6-8].

The aim of this paper was to establish the methodology of testing for cough receptor sensitivity in children, to determine: 1) the tolerance of the test; 2) the repeatability of the test; 3) the effect of IFR on cough receptor sensitivity; and 4) whether short-term tachyphylaxis is present.

\section{Material and methods}

\section{Subjects}

Healthy children with no history of recurrent cough and without an upper respiratory tract infection in the preceding 2 weeks were recruited from the orthopaedic fracture clinic. These children were medically examined to exclude adventitial sounds in the chest, and ear, nose and throat problems. Formal consent was obtained from the parents. The project was approved by the Human Ethics Committee of the hospital.

\section{Study design}

Subjects performed the capsaicin cough receptor sensitivity test described below on at least two occasions. To determine the repeatability of the test, 24 children had the cough challenge repeated at the same IFR (20 $\left.\mathrm{L} \cdot \mathrm{min}^{-1}\right)$. Repeatability tests were performed $1-6$ weeks after the initial test. Both the investigator and subject were blinded to the results of the previous test. In seven children, the challenge was performed with the IFR at 20 and $60 \mathrm{~L} \cdot \mathrm{min}^{-1}$, in random order on different days, to determine the effect of IFR on cough receptor sensitivity. The tests were performed either in the morning $(09: 30-12: 00 \mathrm{~h})$ or the afternoon (14:30-16:30 h). To avoid possible diurnal variation, the subjects returned for the second test at the same time of day. For studies on tachyphylaxis, 10 children repeated the challenge 10 min after completion of the first test, with the same IFR. The outcome measures were cough receptor sensitivity indices defined below.

\section{Capsaicin cough receptor sensitivity challenge test}

The equipment (fig. 1) consisted of a Fleisch pneumotachograph (linear range $9-60 \mathrm{~L} \cdot \mathrm{min}^{-1}$ ) connected to 


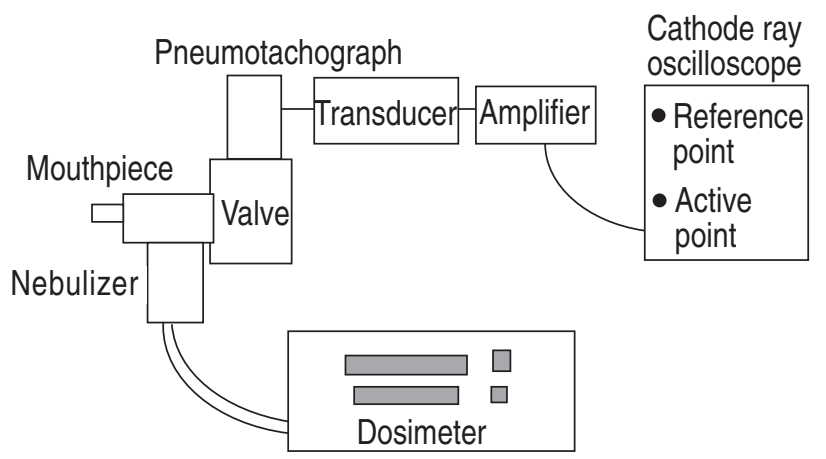

Fig. 1. - Equipment for capsaicin cough challenge.

a nonrebreathing valve (No. 1400; Hans Rudolph, USA) and a reusable jet nebulizer (Durable Sidestream; MedicAid, Sussex, UK). The pneumotachograph was connected to a pressure transducer (4500-50; Vacumetrics, CA, USA) and an amplifier (MC1-3; Validyne, CA, USA). The flow signal was displayed on the lower trace of a two-channel cathode ray oscilloscope (CRO), (5223 Digitalizing Oscilliscope; Tektronix, OR, USA), and the reference point was displayed on the upper trace. The CRO time base was set at $0.5 \mathrm{~s}$. This allowed the subjects to view and thus regulate their inspiratory flow. Solution was delivered through a nebulizer, controlled by a dosimeter (MB3; MEFAR, Italy) set at $0.7 \mathrm{~s}$ inhalation time and a pause time of $30 \mathrm{~s}$. The system was calibrated daily with a flow rater (precision bore flowrater; F \& P, Workington, UK); and a flow of $20 \mathrm{~L} \cdot \mathrm{min}^{-1}$ was set to produce a deflection of one large division. Subjects were encouraged to inhale from functional residual capacity (FRC) and practiced inhaling at a constant flow. The test was commenced when the subjects repeatedly showed that they were able to maintain the same flow for at least $2 \mathrm{~s}$. Subjects were able to visualize their flow rate on the CRO screen. The dosimeter was actuated manually $0.3-0.5 \mathrm{~s}$ after a constant IFR was achieved. The subjects maintained the same IFR during actuation of the dosimeter and for a further 0.3-0.5 s after completion of the actuation.

Capsaicin (8-methyl-N-vanillyl-trans-6-nonenamide) (Sigma-Aldrich, Castle Hill, Australia), dissolved in pure ethanol, was kept as a stock solution at $1 \times 10^{-2} \mathrm{M}$. Further dilutions with $20 \%$ ethanol were made to obtain capsaicin solutions of 1.23 to $1250 \mu \mathrm{M}$. Two millilitres of the test solution were placed in each pot and each actuation of the dosimeter delivered $5 \mu \mathrm{L}$. Subjects inhaled the capsaicin solution in incremental doubling doses at 1 min intervals, after two control pots $(0.9 \%$ saline then $20 \%$ ethanol).

The number of coughs in the $30 \mathrm{~s}$ after actuation of the dosimeter were counted by an independent observer. The end-point was when five or more coughs (C5) were obtained, or when the maximum concentration of capsaicin was achieved. Capsaicin threshold (Cth) was defined as the lowest concentration of capsaicin required to cause $\geq 2$ coughs, $\mathrm{C} 2$ as that producing $2-4$ coughs, and $\mathrm{C} 5$ as that producing $\geq 5$. If the child coughed with the control solutions, then the number of coughs above that produced by the control solution was used.
Analysis

CIA ${ }^{\circledR}$ and SPSS ${ }^{\circledR}$ version 6.0 packages were used. For all comparative data, paired two-tailed Student's t-tests were used after logarithmic transformation of C2, $\mathrm{C} 5$ and $\mathrm{Cth}$. In instances where only $\mathrm{C} 2$ or $\mathrm{C} 5$ values were obtained, the data were omitted for paired analysis. For assessment of repeatability, the following were performed after all data were logarithmically transformed: intraclass correlation (ICC) was calculated [11]; within subject standard deviation (WSSD), otherwise known as single determination of standard deviation (SD) was calculated as SD of difference $/ \sqrt{ } 295 \%$ range for

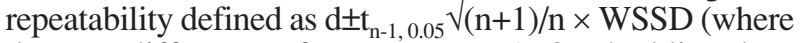
$\mathrm{d}=$ mean difference of measurements) [9]; doubling dose change $=2 \times \mathrm{WSSD} / \log _{10} 2$ [9]; BLAND and Altman [10] plot of mean $v s$ difference of the two measurements.

\section{Results}

The age (mean \pm SEM) of the children tested was $11 \pm 1$ yrs. The challenge was well-tolerated by the children; 28 (93\%) completed the test. The remaining two children, aged 6 and 10 yrs old, stopped the test at 39 and 156 $\mu \mathrm{M}$, respectively due to phalyngeal discomfort. However, this only occurred after they had achieved C2. None of the children coughed with the control solutions. A dose-response effect was demonstrated; the geometric mean of C5 $(79.4 \mu \mathrm{M}$; $95 \%$ confidence interval $(95 \%$

Table 1. - C2, C5 and Cth values obtained on different days, using a constant IFR of $20 \mathrm{~L} \cdot \mathrm{min}^{-1}$

\begin{tabular}{rrrrrrrr}
\hline Pt & Age & \multicolumn{3}{c}{ Test 1 $\mu M$} & \multicolumn{3}{c}{ Test 2 $\mu M$} \\
No. & yrs & C2 & Cth & \multicolumn{1}{c}{ C5 } & C2 & Cth & C5 \\
\hline 1 & 10 & 156 & 156 & 312.5 & 156 & 156 & 625 \\
2 & 14 & 39 & 39 & 625 & 39 & 39 & 1250 \\
3 & 11 & 39 & 39 & & 19.5 & 19.5 & \\
4 & 11 & 19.5 & 19.5 & 39 & 39 & 39 & 78 \\
5 & 11 & 9.8 & 9.8 & 19.5 & 9.8 & 9.8 & 19.5 \\
6 & 10 & & 78 & 78 & 39 & 39 & 78 \\
7 & 13 & 19.5 & 19.5 & 19.5 & 9.8 & 9.8 & 19.5 \\
8 & 6 & 39 & 39 & & 19.5 & 19.5 & \\
9 & 13 & 39 & 39 & 312.5 & 39 & 39 & 156 \\
10 & 12 & 9.8 & 9.8 & 39 & 9.8 & 9.8 & 39 \\
11 & 14 & & 39 & 39 & & 39 & 39 \\
12 & 11 & 19.5 & 19.5 & 39 & 19.5 & 19.5 & 78 \\
13 & 10 & & 39 & 39 & & 19.5 & 19.5 \\
14 & 12 & 19.5 & 19.5 & 78 & 19.5 & 19.5 & 156 \\
15 & 13 & 78 & 78 & 156 & 78 & 78 & 156 \\
16 & 12 & & 78 & 78 & 78 & 78 & 156 \\
17 & 16 & & 78 & 78 & 39 & 39 & 78 \\
18 & 6 & & 156 & 156 & 39 & 39 & 312.5 \\
19 & 9 & & 19.5 & 19.5 & & 39 & 39 \\
20 & 7 & & 78 & 78 & 39 & 39 & 156 \\
21 & 16 & 156 & 156 & 1250 & 156 & 156 & 1250 \\
22 & 14 & 19.5 & 19.5 & 78 & 9.8 & 9.8 & 39 \\
23 & 16 & 19.5 & 39 & 1250 & 19.5 & 19.5 & 1250 \\
24 & 7 & 9.8 & 9.8 & 156 & 19.5 & 19.5 & 156 \\
\hline & & & & & & &
\end{tabular}

Pt: patient; $\mathrm{C} 2$ : concentration of capsaicin required to stimulate 2-4 coughs; C5: concentration of capsaicin required to stimulate $\geq 5$ coughs; Cth: threshold concentration of capsaicin required to stimulate $\geq 2$ coughs; IFR: inspiratory flow rate. 
CI) 45.7-275.4) was significantly higher than C2 (26.3 $\mu \mathrm{M}$; CI 15.5-61.7) $(\mathrm{p}=0.00001)$. A C2 value was not obtainable in all children, as sometimes the first coughing episode resulted in $\geq 5$ coughs, thus, only $\mathrm{Cth}$ and C5 values were obtained.

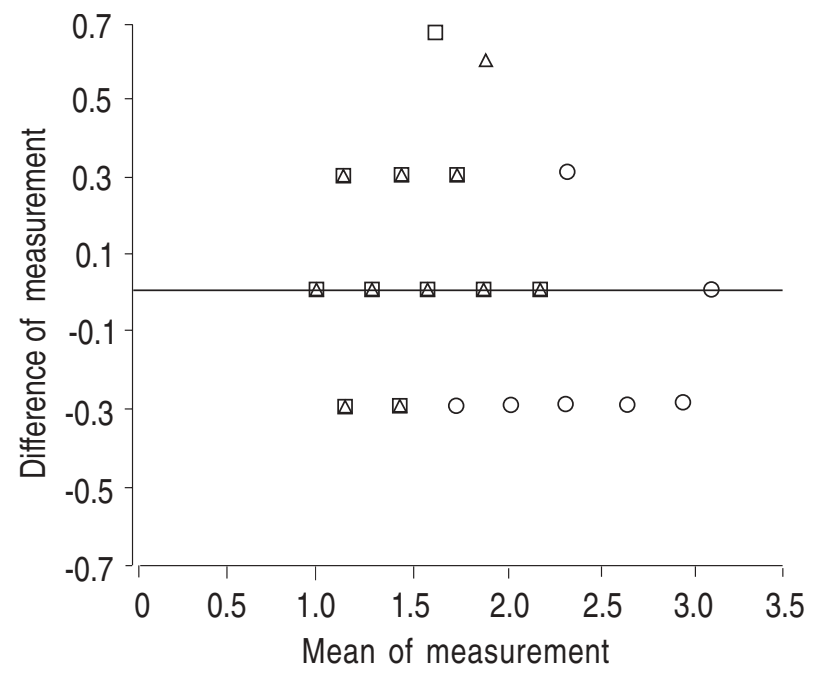

Fig. 2. - Graph of difference in measurement $v s$ the mean of test 1 and 2 (Bland and Altman [10] plot). Axis numbers are in log values. $\mathrm{O}$ : $\mathrm{C} 5$, i.e. concentration of capsaicin required to stimulate $\geq 5$ coughs; $\square$ : $\mathrm{C} 2$, i.e. concentration of capsaicin required to stimulate 2-4 coughs; $\Delta$ : Cth, i.e. threshold concentration of capsaicin required to stimulate $\geq 2$ coughs.

Table 2. - Data on the indices of repeatability

\begin{tabular}{lccc}
\hline & $\mathrm{C} 2$ & $\mathrm{C} 5$ & $\mathrm{Cth}$ \\
\hline Subjects n & 16 & 22 & 24 \\
Mean of difference & 0.08 & -0.09 & 0.10 \\
WSSD & 0.17 & 0.15 & 0.16 \\
95\% CI & $(-0.28-0.44)$ & $(-0.41-0.23)$ & $(-0.43-0.33)$ \\
Coefficient of & 0.34 & 0.31 & 0.33 \\
$\quad$ repeatability & & & \\
ICC & 0.80 & 0.91 & 0.78 \\
Doubling dose & 1.13 & 1.03 & 1.08 \\
\hline
\end{tabular}

Tests were repeated at a constant IFR of $20 \mathrm{~L} \cdot \mathrm{min}^{-1}$. Numbers are in log values. ICC: intraclass correlation; WSSD: within subject standard deviation; 95\% CI: $95 \%$ confidence interval. For further definitions see legend to table 1.

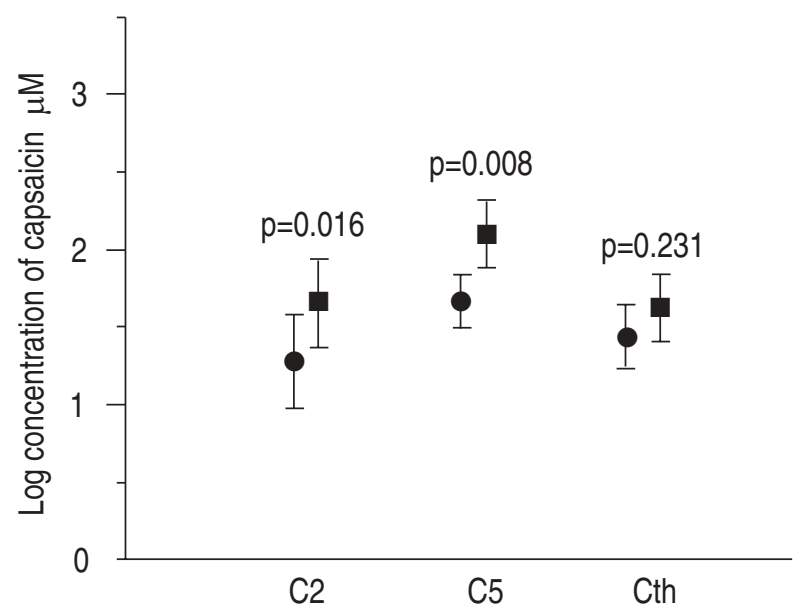

Fig. 3. - Effect of inspiratory flow rate (IFR) on $\mathrm{C} 2$, C5 and Cth. Values are presented as mean \pm SEM. 0 : IFR of $20 \mathrm{~L} \cdot \mathrm{min}^{-1}$; $\mathbf{\square}$ : IFR of $60 \mathrm{~L} \cdot \mathrm{min}^{-1}$. For definitions see legend to figure 2 .
The results of the tests performed on different days at the same IFR $\left(20 \mathrm{~L} \cdot \mathrm{min}^{-1}\right)$ for the repeatability study are shown in table 1 and figure 2 (BLAND and Altman [10] plot). The statistical analysis for repeatability is summarized in table 2 . Cth, $\mathrm{C} 2$ and $\mathrm{C} 5$ are highly repeatable when the IFR is constant.

The effect of changing the IFR on different test days, on the same individuals, is depicted in figure 3. Increasing the IFR from 20 to $60 \mathrm{~L} \cdot \mathrm{min}^{-1}$ significantly increased C2 (geometric mean of 19.5 and $46.8 \mu \mathrm{M}$, respectively, $\mathrm{p}=0.016$ ) and C5 (geometric mean of 46.8 and 128.8 $\mu \mathrm{M}$, respectively, $\mathrm{p}=0.008$ ). Cth was also increased (geometric mean of 28.8 and $43.7 \mu \mathrm{M}$, respectively) with tripling the IFR, but the change was not significant $(\mathrm{p}=0.231)$.

There was no significant change in the geometric mean when the challenge was repeated 10 min later for $\mathrm{C} 2$, C5 and Cth.

\section{Discussion}

We have shown, in this study, that in children the capsaicin cough receptor sensitivity test is well-tolerated, repeatable and is influenced by IFR. The advantage of using capsaicin as a tussive agent in clinical studies was demonstrated by CHOUDRY and co-workers [7], who showed that cough reflex sensitivity to capsaicin is significantly different in those with a productive cough in comparison to those with a nonproductive cough. However, for tests to be useful clinically for therapeutic interventions, or for comparative research purposes, information on the repeatability of tests is important. In the assessment of patients, a clinically significant change in measurement has to lie beyond the 95\% range [9]. Studies on cough receptor sensitivity in adults have described estimates of repeatability using analysis of variance $[13,14]$ or correlation methods [6], whilst other studies using capsaicin have not included repeatability measurements for the laboratory $[2,3]$. In our study, we have demonstrated that the capsaicin cough challenge test is repeatable for $\mathrm{C} 2, \mathrm{C} 5$ and $\mathrm{Cth}$, if the IFR is constant.

We have also shown that it is important to standardize the IFR, a factor not considered in the clinical papers involving capsaicin $[2,3]$. The geometric mean was significantly affected when the IFR was not standardized; the repeatability of the test, thus, becomes irrelevant, when the IFR is not controlled. The higher IFR significantly increased C2 and C5 values. This is likely to be related to the site of deposition of capsaicin particles with different IFRs. This finding is similar to that of HANSSON et al. [12], although the arrangement of the delivery system was different. In contrast, BARROS et al. [8] found a negative relationship between IFR and the cough response. The difference between the findings of the present study and that of BARROS et al. [8] is likely to be related to the different IFR used. BARROS et al. [8] used IFRs of $50-150 \mathrm{~L} \cdot \mathrm{min}^{-1}$, whilst HANSSON et al. [12] used 15 and $60 \mathrm{~L} \cdot \mathrm{min}^{-1}$, more like the present study in which IFRs of 20 and $60 \mathrm{~L} \cdot \mathrm{min}^{-1}$ were used. Capsaicin-induced cough was initially thought to be caused by stimulation of capsaicin-sensitive nerve terminals in the larynx [6]. However, Hansson et al. [12] demonstrated the presence of intrapulmonary capsaicinsensitive sensory neurones, which appear to be more 
sensitive than those in the larynx. More recently, capsaicin (vallinoid) receptors have been characterized in human airways [15]. We used a low IFR, as the test is intended for paediatric use, and at higher IFR it was not possible to reliably actuate the dosimeter while maintaining a constant IFR pre- and postactuation despite a short delivery time of $0.7 \mathrm{~s}$. Other studies $[2,3,8]$ used a longer delivery time, $0.9-1.0 \mathrm{~s}$. In an earlier pilot study (unpublished data), we found that most children aged 6-8 yrs were unable to consistently maintain an IFR of $20 \mathrm{~L} \cdot \mathrm{min}^{-1}$ for more than $2 \mathrm{~s}$.

The present results are similar to other studies showing a dose response $[6,7]$. However, the $\mathrm{C} 2(26.3 \mu \mathrm{M})$ and C5 $(79.4 \mu \mathrm{M})$ values in these children are different from those of the normal subjects of CHOUDRY et al. [1] $(\mathrm{C} 2=9.5 \mu \mathrm{M}$; $\mathrm{C} 5=60.3 \mu \mathrm{M})$. This is possibly related to a number of factors, including the differences in age, the type of delivery system, the method of inhalation, the timing of the actuation of the dosimeter, the factors affecting aerosol particle size, the IFR and potency of varieties of capsaicin.

We were unable to demonstrate the presence of shortterm tachyphylaxis in children, in agreement with other studies on adults [6-8], but in contrast to the study by MORICE et al. [13] who found that tachyphylaxis was present for as long as $240 \mathrm{~min}$. C2, C5 values were both higher when the test was repeated immediately, but the difference was not statistically significant. As with the other studies, it is possible that a type 2 error may have occurred. Until a larger study is performed, we suggest that, for comparative studies, the test is repeated on a different day.

Data on the possible effect of diurnal variation on capsaicin cough receptor sensitivity is not available. Some studies did not state if the test was repeated at the same time of the day [3, 6, 12]. Like other studies [13], these tests were performed at the same time of day for the studies on repeatability and the effect of IFR. Until further data are available, we suggest that the test is performed at the same time of the day for comparative studies.

We have shown that the capsaicin cough challenge test for cough receptor sensitivity is well tolerated in children. The test is highly repeatable for determination of the concentration of capsaicin required to stimulate 2-4 coughs (C2), and $\geq 5$ coughs (C5), and the lowest concentration required to stimulate $\geq 2$ coughs ("threshold" Cth). It can thus be used for comparative clinical studies in children, if the inspiratory flow is regulated.
Acknowledgement: The authors thank J. Carlin for his significant contribution to statistical methods.

\section{References}

1. Choudry NB, Fuller RW. Sensitivity of the cough reflex in patients with chronic cough. Eur Respir J 1992; 5: 298-300.

2. Ferrari M, Oliveri M, Sembenini C, et al. Tussive effect of capsaicin in patients with gastroesophageal reflux without cough. Am J Respir Crit Care Med 1995; 151: $557-561$.

3. O'Connell F, Thomas VE, Pride NB, Fuller RW. Capsaicin cough sensitivity decreases with successful treatment of chronic cough. Am J Respir Crit Care Med 1994; 150: 374-380.

4. Chai H, Farr RS, Froehlich LA, et al. Standardisation of bronchial inhalation challenge procedures. J Allergy Clin Immunology 1975; 56: 323-327.

5. Yan K, Salome C, Woolcock AJ. Rapid method for measurement of bronchial responsiveness. Thorax 1983; 38: 760-765.

6. Collier JG, Fuller RW. Capsaicin inhalation in man and the effects of sodium cromoglycate. Br J Pharmacol 1984; 81: 113-117.

7. Choudry NB, Fuller RW, Anderson N, Karlsson JA. Separation of cough and reflex bronchoconstriction by inhaled local anaesthetics. Eur Respir J 1990; 3: 579583.

8. Barros MJ, Zammattio SL, Rees PJ. Effect of change in inspiratory flow rate on cough responses to inhaled capsaicin. Clin Sci 1991; 81: 539-542.

9. Chinn S. Repeatability and method comparison. Thorax 1991; 46: 454-456.

10. Bland JM, Altman DG. Statistical methods for assessing agreement between two methods of clinical measurement. Lancet 1986; i: 307-308.

11. Armitage P, Berry G. Further experimental designs. In: Statistical Methods in Medical Research. 3rd Edn. Oxford, Blackwell Scientific Publications,1994; pp. 273-276.

12. Hansson L, Wollmer P, Dahlback M, Karlson J. Regional sensitivity of human airways to capsaicin-induced cough. Am Rev Respir Dis 1992; 145: 1191-1195.

13. Morice AH, Higgins KS, Yeo WW. Adaptation of cough reflex with different types of stimulation. Eur Respir $J$ 1992; 5: 841-847.

14. Midgren B, Hansson L, Karlson JA, Simonsson BG, Persson CGA. Capsaicin-induced cough in humans. Am Rev Respir Dis 1992; 146: 347-351.

15. Szallazi A, Goso C, Manzini S. Resiniferatoxin binding to vallinoid receptors in guinea-pig and human airways. Am J Respir Crit Care Med 1995; 152: 59-63. 